\title{
Erratum to: Do Chinese Children Believe in an Afterlife?
}

\author{
Liqi Zhu
}

\section{Erratum to:}

Chapter 10 in: R.G. Hornbeck et al. (eds.), Religious Cognition in China, New Approaches to the Scientific Study of Religion 2, https://doi.org/10.1007/978-3-319-62954-4_10

Chapter 10 was incorrectly published with the following co-authors "Jonathan D. Lane, E. Margaret Evans, and Henry M. Wellman". Now these authors have been removed from Chapter 10. 